\title{
Power Transformer Control by Neuro Fuzzy Controller and Haar Wavelet Transform
}

\author{
Mohammed Faisal M. Wafeek ${ }^{1}$, Ch. Punya Sekhar ${ }^{2}$ \\ ${ }^{1}$ PG Scholar, Dept. of EEE, University College of Engineering \& Technology, Acharya Nagarjuna University, Guntur, 522510, Andhra \\ Pradesh, India.Andhra Pradesh, India. \\ ${ }^{2}$ Assistans Professor, Dept. of EEE, University College of Engineering \& Technology, Acharya Nagarjuna University, Guntur, 522510,
}

\begin{abstract}
Wavelet transforms are fast and efficient means of analyzing transient voltage and current signals. Compare with fast Fourier transform, wavelet transform gives better results in analyzing signals containing sharp spikes. Differential protection schemes are widely used by electric companies to protect power equipments. Normally, various techniques are used in power transformer protection. This paper proposed novel control technique for transformer protection. This protection approach is based on extracting the fundamental components present in differential currents. This paper aims to prove that the Wavelet Transform is a reliable and computationally efficient tool for fault currents. The aneural network based fuzzy logic controller is used to design protection relay for transformer. The simulation is done by MATLAB/SIMULINK software and results are shown clearly in this paper.
\end{abstract}

Keywords: Fast Fourier transform, wavelet transform, artificial neural network and fuzzy logic controller

\section{Introduction}

A transformer is a static electrical device used in electric power systems to transfer power between circuits through the use of electromagnetic induction. When an alternating current flows in a conductor, a magnetic field exists in the conductor. The term power transformer is used to refer those transformers used in the generation and distribution circuits. These power transformers must be used at each of the points where there is a transition between voltage levels. Transformers experience large inrush currents that are rich in harmonic content at the time of switching.Although an electrical power transformer is a static device, but internal stresses arising from abnormal system conditions, must be taken into consideration. A transformer generally suffers from following types of transformer fault.

1) Over current due to overloads and external short circuits,

2) Terminal faults,

3) Winding faults,

4) Incipient faults.

In case of sustained overload conditions, the transformer should not be allowed to operate for long duration. To improve the lifetime of power transformer we need a protection system. There are so many factors to affect the power transformer functions.Some of those factors are magnetizing inrush current, fault current and over excitation parameters.In this paper a method for protecting and monitoring power transformers based on fuzzy logic along with the application of wavelet transform is proposed. Normally differential protection relays are used for transformer protection. The differential current of primary and secondary side of the transformer is essential to identify the fault occurrence.

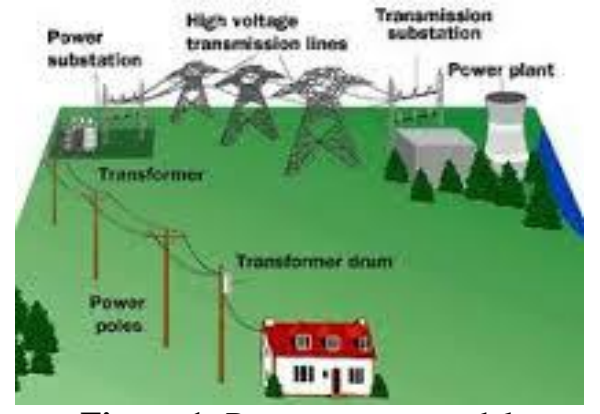

Figure 1: Power system model

To overcome this difficulty and prevent the malfunction of differential relay, many methods have been presented to analyze and recognize inrush current and internal fault currents. As both inrush current and internal faults are nonstationary signals, wavelet based signal processing technique is an effective tool for power system analyze and feature extraction. However the wavelet-based methods have better ability of time-frequency analysis, but they usually require long data windows and are also sensitive to noise. The method presented in [6] uses WT and ANFIS to discriminate internal faults from inrush current. Since the values of wavelet coefficients at detail 5 (D5) are used for pattern recognition process, the algorithm is very sensitive to noise.

\section{Discrete Wavelet Transform:}

Differential protection algorithms based on FFT have disadvantages, including the neglecting of high frequency harmonics. Furthermore, different windowing techniques should be applied to calculate the currentand voltage phases and this causes significant time delay for the protection relay. In this case, accuracy isnot completely assured. Due to increased standards of the delivered energy quality such as IEEE 519, highperformance algorithms should be taken into account.The Grossmann \& Morlet (1984) definition of the continuous wavelet transform (CWT) for a 1-Dsignal $f(x) 2$ $L 2(R)$ is 


\section{International Journal of Science and Research (IJSR) \\ ISSN (Online): 2319-7064 \\ Index Copernicus Value (2013): 6.14 | Impact Factor (2015): 6.391}

$W(a, b)=k(a) \int_{-\infty}^{\infty} f(x) \quad \bar{\Psi}((b-x) / a) d x$

Where ' $a$ ' and ' $b$ ' are the positional parameters. The continuous nature of the wavelet functionis kept up to the point of sampling the scale-translation grid used to represent the wavelet transform isindependent of the sampling of the signal under analysis.

The Fourier transform is a useful tool to analyze the frequency components of the signal. However, if we take the Fourier transform over the whole time axis, we cannot tell at what instant a particular frequency rises. Wavelets are a mathematical tool, that can be used to extract information from many kinds of data, including audio signals and images.The discrete wavelet transform (DWT) is an implementation of the wavelet transform using a discrete set of the wavelet scales and translations obeying some defined rules. In other words, this transform decomposes the signal into a mutually orthogonal set of wavelets.

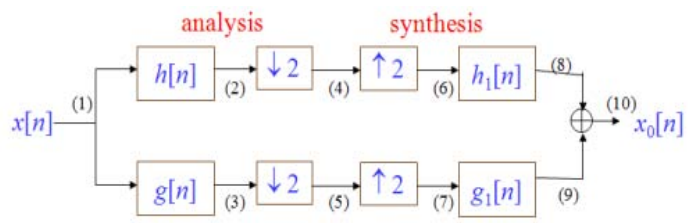

Figure 2: Wavelet transform

The discrete wavelets can be made orthogonal to their own dilations and translations by special choices of the mother wavelet, which means,

$$
\int \psi_{j, k}(t) \psi^{*} m_{m, n}(t) d t=\left\{\begin{array}{r}
1 \text { if } j=m \text { and } k=n \\
0 \text { otherwise }
\end{array}\right\}
$$

An arbitrary signal can be reconstructed by summing the orthogonal wavelet basis functions, weighted by the wavelet transform coefficients,

$$
F(t)=\sum_{j, k} \gamma(j, k) \psi_{j, k}(t)
$$

Where $i$ and $j$ are integers, the functions $\Psi i, j(t)$ are thewavelet expansion functions and the two parameters expansioncoefficients $i, j$ is called the discrete wavelet transform(DWT) coefficients of $f(t)$.

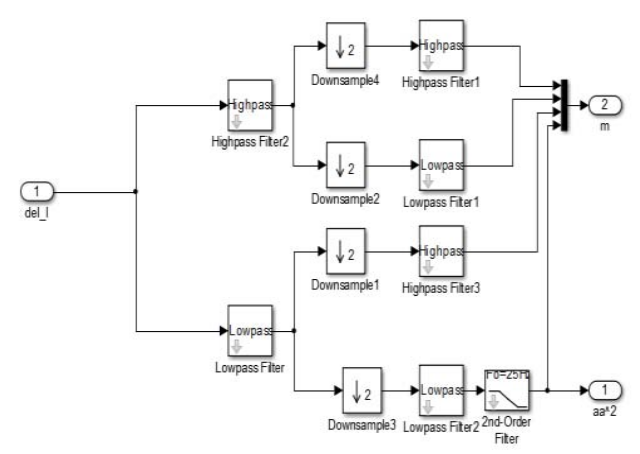

Figure 3: Simulink model of wavelet transform

\section{Neuro Fuzzy Control}

The operating principle of fuzzy logic controller is similar to the human operator. It performs the sameactions as a human operator does by adjusting the inputsignal looking at only the system output. The fuzzysystem is used to deal with the input without the dataloss. Fuzzy logic has three steps as given below.

1) Fuzzification (converting crisp values into fuzzyvalues).

2) Inference mechanism (Rule base and If-Then rules).

3) Defuzzification (converting fuzzy values into crispvalues).

The Classical control theory is based on the mathematical models that describe the physical plant under consideration. The essence of fuzzy control is to build a model of human expert who is capable of controlling the plant without thinking in terms of mathematical models. The transformation of expert's knowledge in terms of control rules to fuzzy framework has not been formalized and arbitrary choices concerning, for example, the shape of membership functions hasto be made. The quality of fuzzy controller can be drastically affected by the choice of membership functions. Thus, methods for tuning the fuzzy logic controllers are needed.

In this paper, neural networks are used in a novel way to solve the problem of tuning a fuzzy logic controller. The Neuro fuzzy controller uses the neural network learning techniques to tune the membership functions while keeping the semantics of the fuzzy logic controller intact. Both the architecture and the learning algorithm are presented for a general Neuro fuzzy controller. From this general Neuro fuzzy controller, a proportional Neuro fuzzy controller is derived. A step by step algorithm for off-line training is given along with numerical examples.

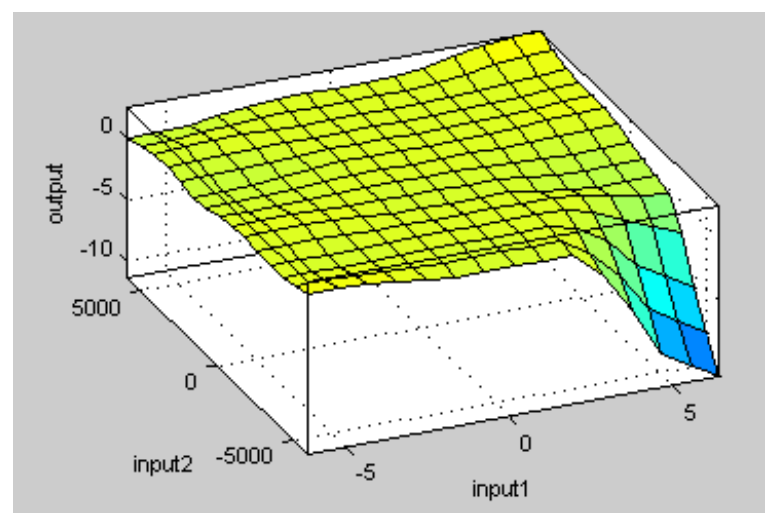

Figure 4: Surface viewer

\section{Simulation and Results}

The 13.8/138V system is modeled by using MATLAB/SIMULINK software. As shown in Fig.5The source issimulated by an equivalent $50 \mathrm{~Hz}$ 30MVA Synchronousmachines with 500 MVA transformer and 50 MW load isconnected in parallel. A .8(13/138) kV star to delta connectedtransformer is employed with its neutral grounded. The generator $X /$ Rratio is 7 . The primary winding voltage $R(p u)$ and $L(p u)$ are $13.8 \mathrm{kV} .0 .0078$ and 0.259 respectively, and secondarywinding voltage is $R(p u)$ and $L(p u)$ are $138 \mathrm{k} . \mathrm{V} 0.0078$ and0.259 respectively. The load taken hereis $50 \mathrm{MW}$ and $10 \mathrm{MVAR}$. 


\section{International Journal of Science and Research (IJSR) \\ ISSN (Online): 2319-7064}

Index Copernicus Value (2013): 6.14 | Impact Factor (2015): 6.391

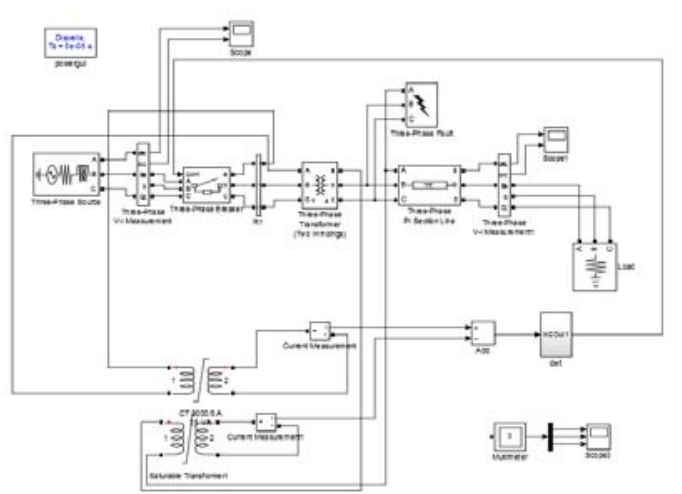

Figure 5: Matlab Simulink Model

\subsection{Simulation of Neuro fuzzy controller}

To identify the fault currents in transmission system various technique are used. The current in primary and secondary side of the transformer are measured by using current transformer. As shown in fig. 3 From this differential current approximation and detailed coefficients were detected by discrete wavelet transform. From the approximation coeffitients relaying algorithm is derived by using Neuro fuzzy.

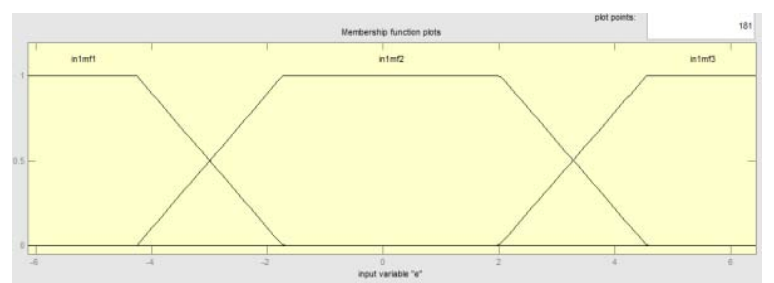

Figure 6: (a) Membership function of e

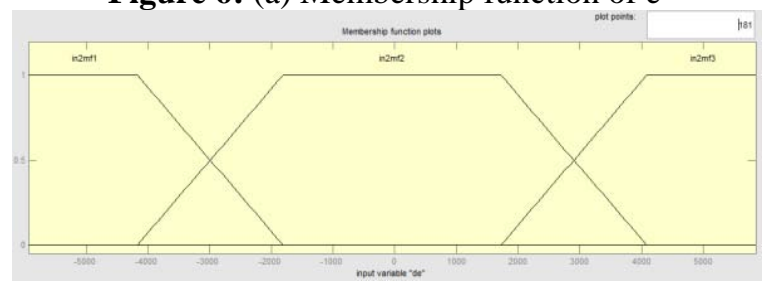

Figure 6: (b) Memebership function of de

A neuro-fuzzy system is based on a fuzzy system which is trained by a learning algorithm derived from neural network theory. The (heuristical) learning procedure operates on local information, and causes only local modifications in the underlying fuzzy system.As shown in fig.8 a neuro-fuzzy system can be viewed as a 3-layer feedforward neural network. The first layer represents input variables, the middle (hidden) layer represents fuzzy rules and the third layer represents output variables. Fuzzy sets are encoded as (fuzzy) connection weights. It is not necessary to represent a fuzzy system like this to apply a learning algorithm to it. Inputs to the fuzzy controller is shown in fig.6(a) and 6(b). However, it can be convenient, because it represents the data flow of input processing and learning within the model.The learning procedure of a Neuro-fuzzy system takes the semantical properties of the underlying fuzzy system into account. This results in constraints on the possible modifications applied to the system parameters.

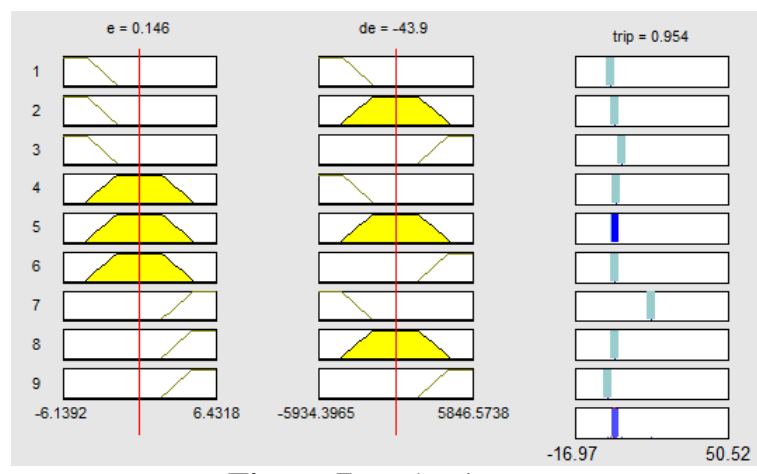

Figure 7: Rule viewer

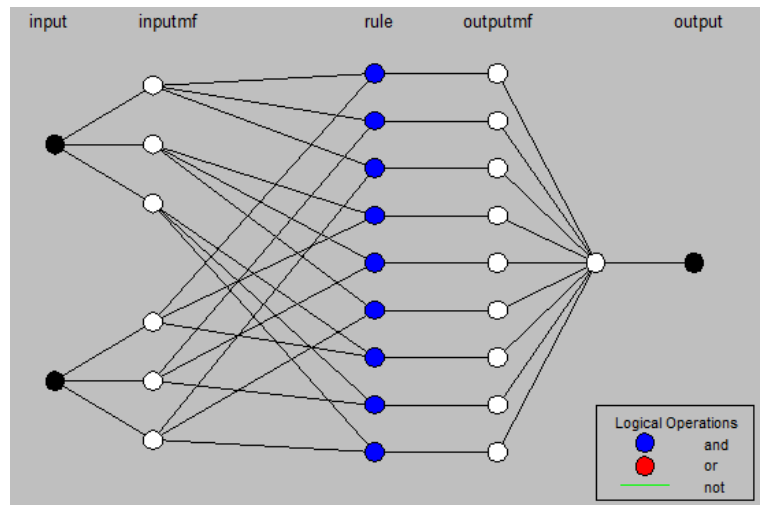

Figure 8: Neuro fuzzy structure

Fuzzy Logic Toolbox. Membership Functions. A membership function (MF) is a curve that defines how each point in the input space is mapped to a membership value (or degree of membership) between 0 and 1.

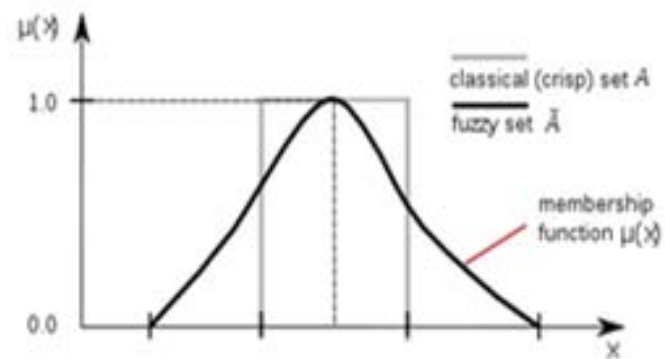

Figure 9: MF of fuzzy set

Membership functions on $\mathrm{x}$ represent fuzzy subsets X. The membership function which represents a fuzzy set $\mathrm{A}$ is usually denoted by $\mu$ For an element $X$ of $X$,the value $\mu \mathrm{A}(\mathrm{x})$ is called the membership degree of $\mathrm{X}$ in the fuzzy set $A$. The membership degree $\mu \mathrm{A}(\mathrm{x})$ quantifies the grade of membership of the element $X$ to the fuzzy set .The value 0 means that $X$ is not a member of the fuzzy set; the value 1 means that $X$ is fully a member of the fuzzy set. The values between 0 and 1 characterize fuzzy members, which belong to the fuzzy set only partially.

\section{Results}

The Voltage and current waveforms for various conditions (without fault, with fault and with tripping algorithm) are shown in the figures below. Fig.10(a) - (b) and Fig.11(a) (b) represented Voltage and current waveforms under normal condition at no fault in a transmission line. 


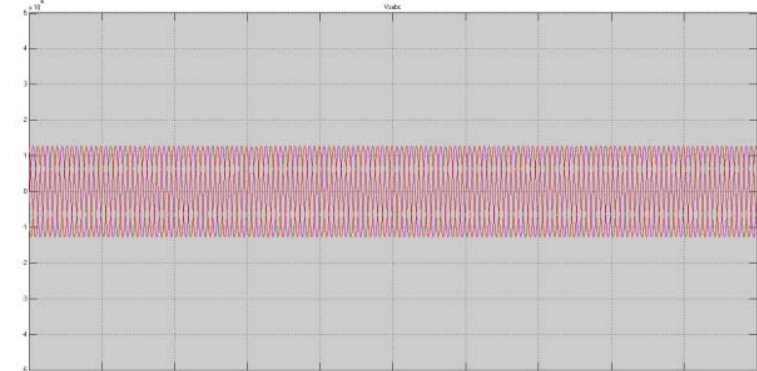

Figure 10: (a) Grid V under normal condition

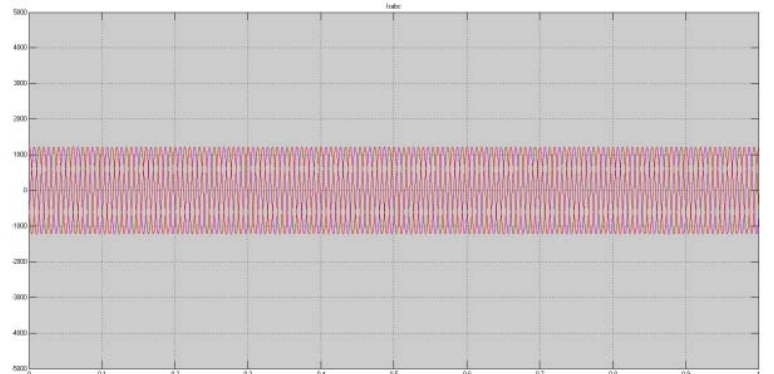

Figure 10: (b) Grid I under normal condition

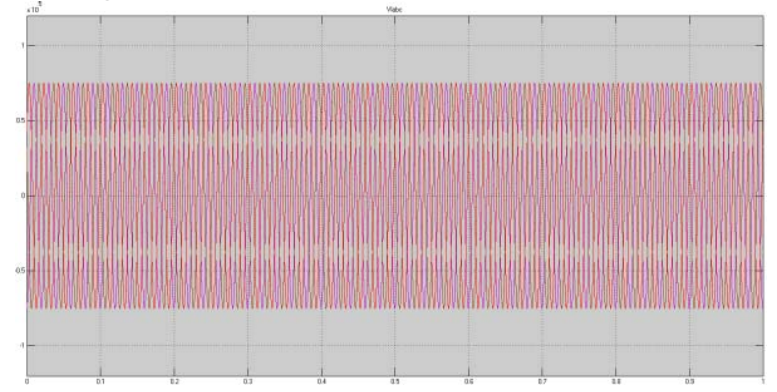

Figure 11: (a) The Load V under normal condition

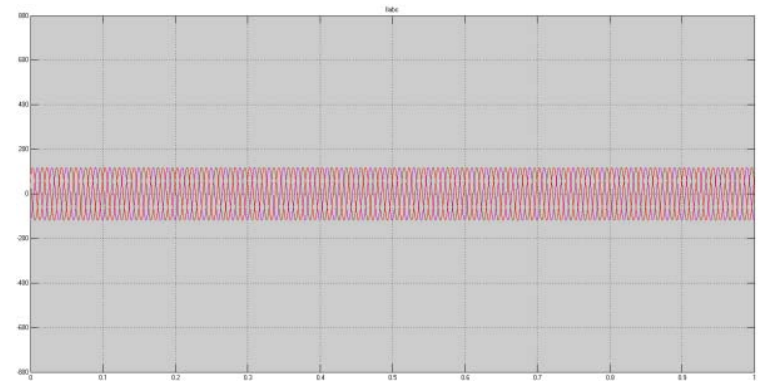

Figure 11: (b) The Load I under normal condition

At the time of 0.5 Seconds three-phase to ground fault is applied to a transmission line. Due to the fault, voltage dip and sudden abnormal currents are shown in Fig.12(a) - (b) and Fig.13(a) - (b).

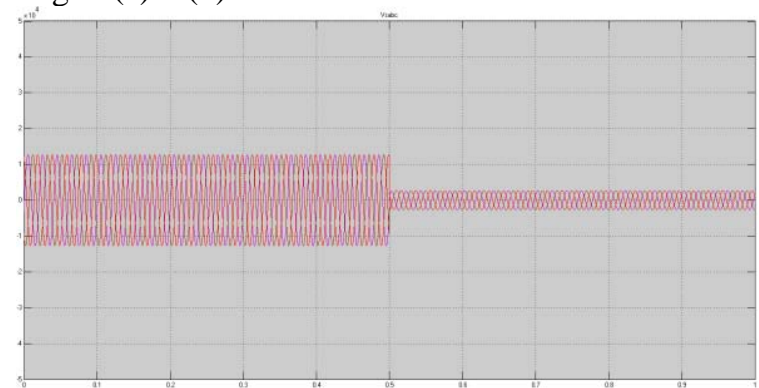

Figure 12: (a) source V during Three phase fault

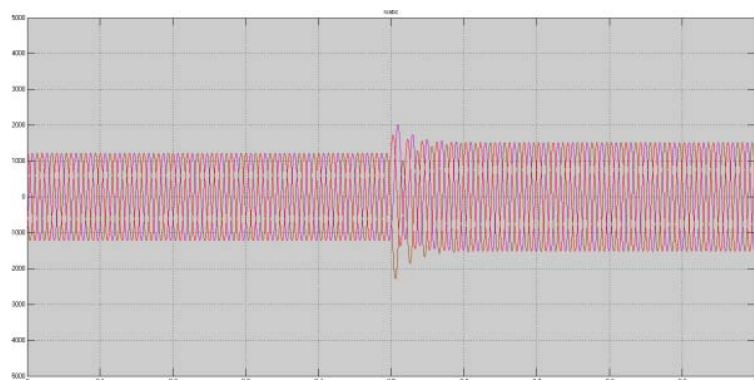

Figure 12: (b) source V duringThree phase fault

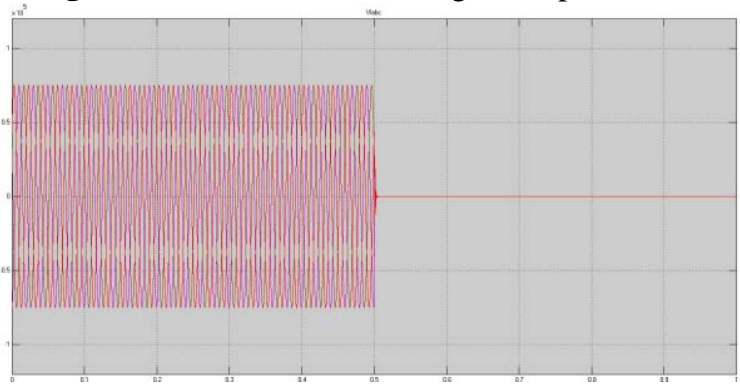

Figure 13: (a) The Load V during Three phase fault

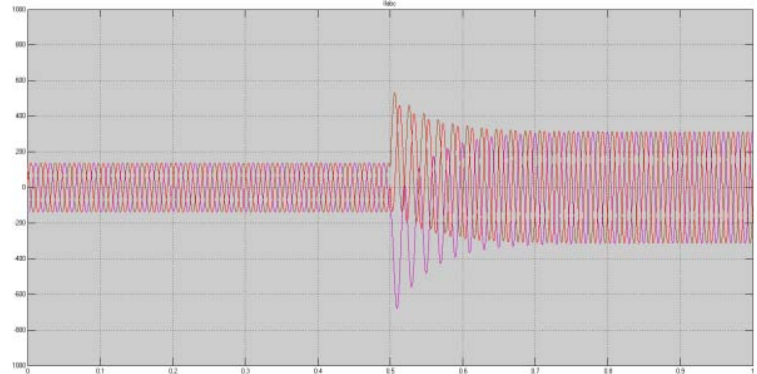

Figure 13: (b) The Load I during Three phase fault

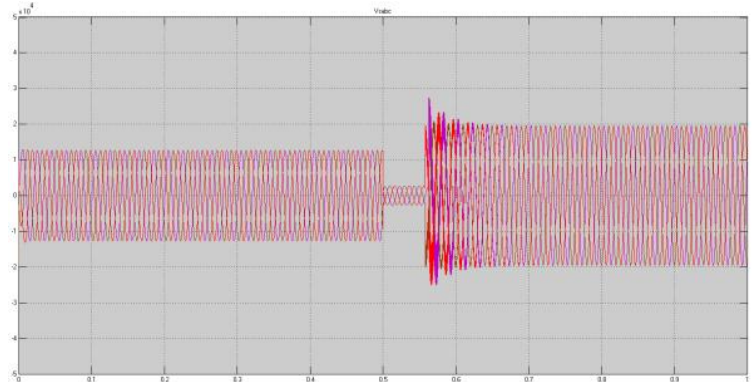

Figure 14: (a)The Source V with relay protection

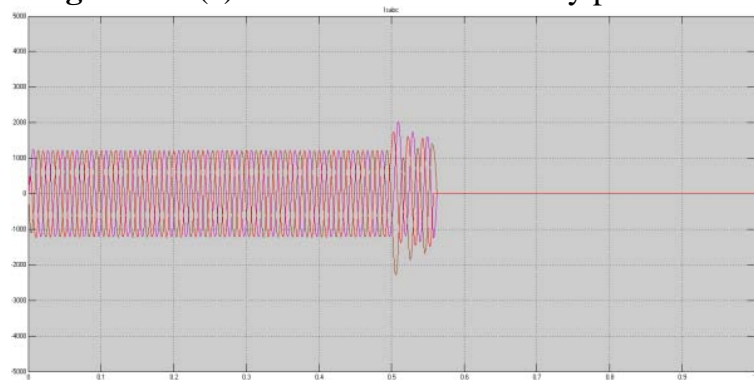

Figure 14: (b) The Source I with relay protection 


\section{International Journal of Science and Research (IJSR) \\ ISSN (Online): 2319-7064}

Index Copernicus Value (2013): 6.14 | Impact Factor (2015): 6.391

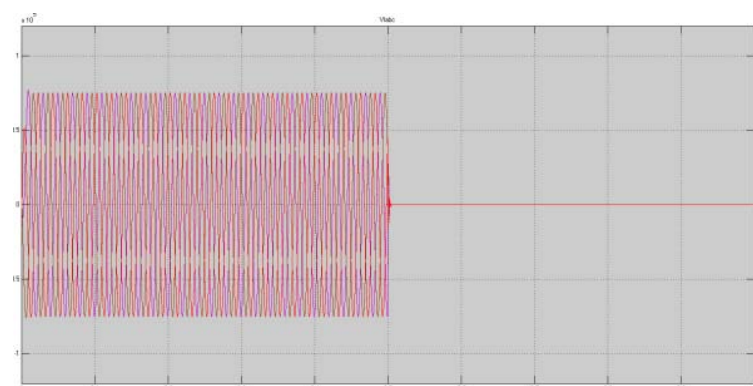

Figure 15: (a) The Load V with relay protection

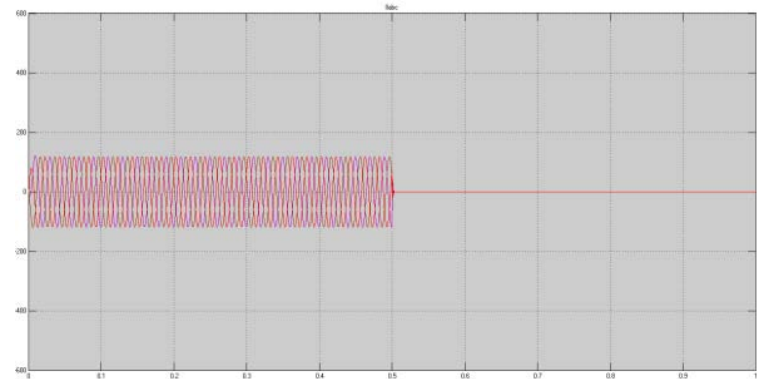

Figure 15: (b) The Load I with relay protection

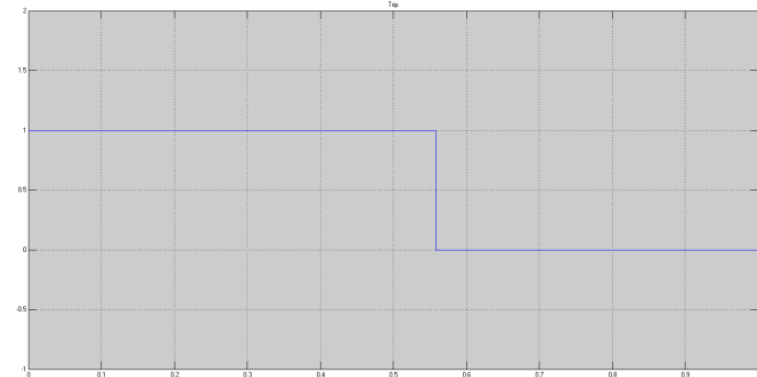

Figure 16: The Trip signal to circuit breaker

After identifyingthe fault occurence, the tripping signal is created by the Neuro fuzzy controller. This tripping command will be given to the circuit breaker to open. So that the power transformer can protect from faults. In this paper clearly we have shown the waveforms of voltage and current waveforms at source and load side (after applying relaying algorithm ) is shown in Fig.14(a) - (b) and Fig.15(a) - (b).

\section{Conclusion}

In the present work wavelet transform,fuzzy controller and Neuro fuzzy controller are used to protect power transformers from faults. The simulation results show that the protection system based on wavelet transform is suitable for relay protection for all types of fault. A simple decision making logic scheme using fuzzy logic ANFIS is presented for the developed technique forfaults identification.The simulation waveforms show that the Neuro fuzzy based relays are tripping properly during the faulty condition. The extensive simulation results presented show thatthe proposed technique needs very simple inputsignals.

\section{References}

[1] P.Bastard, M.Meunier, and H.Regal, Neural networkbased algorithm for power transformer differential relays, IETGeneration Trans. \& Distr.,vol.142, pp.386392,1995.
[2] P.L.Mao, R.K.Aggarwal, A wavelet transform based decision making logic method for discrimination between internal faults and inrush current in power transformers, Electric Power System Research, vol. 22,pp. 389-395,June 2000.

[3] P. Liu, 0. P. Malik, C. Chen, G. S. Hope, and Y. Guo,"Improved operation of differential protection of power transformers for internal faults", IEEE Trans. Power Del.,vol. 7, no. 4, page(s): 1912-1919, Oct. 1992.

[4] Biswarup Das; J.Vittal Reddy, "Fuzzy-Logic-Based Fault Classification Scheme for DigitalDistance Protection", IEEE Transactions on PowerDelivery, Vol.20, Issue 2, Page(s): 609 - 616, Apri2005

[5] Ramsis S. Girgis, Ed G. teNyenhuis, - Characteristics of Inrush Current of Present Designs of Power Transformersl,IEEE，1-4244-1298-6/07/\$25.00 @2007 IEEE.

[6] M. Fedi, et al., Joint Application of Continuous and Discrete Wavelet Transform on Gravity Data to Identify Shallow and Deep Sources, International Journal of Geophys, 156, 7-21, 2004.

[7] M.A. Rahman, B. So, M. R. Zaman, M.A. Hoque", Testing of Algorithms for A Stand-Alone Digital Relay for Power Transformers, IEEE Transactions on Power Delivery, Vol. 13, No. 2, April 1998.

[8] EI Safty.S, Gharieb,S, EI Latif Badr.A, M.Mansour.: A wavelet fuzzy expert technique for classification ofpower transformer transients. In: Internationalconference on power system technology, p. 1-5, June2006. 